\title{
Consenso $\mid$ Protocolo Brasileiro para Infecções Sexualmente Transmissíveis 2020: infecções que causam úlcera genital
}

doi: 10.1590/S1679-4974202100010.esp1

\author{
Brazilian Protocol for Sexually Transmitted Infections 2020: infections that \\ cause genital ulcers
}

\section{Protocolo Brasileño para Infecciones de Transmisión Sexual 2020: infecciones que causan úlcera genital}

\author{
Mauro Cunha Ramos ${ }^{1}$ - (1) orcid.org/0000-0003-4341-2390 \\ José Carlos Sardinha² - (D) orcid.org/0000-0003-2177-0904 \\ Herculano Duarte Ramos de Alencar ${ }^{3}$ - (1) orcid.org/0000-0002-9834-6135 \\ Mayra Gonçalves Aragón ${ }^{4}$ - (1) orcid.org/0000-0001-6631-1790 \\ Leonor Henriette de Lannoy ${ }^{4}$ - (D) orcid.org/0000-0002-9520-8538 \\ 1Secretaria de Estado de Saúde do Rio Grande do Sul, Ambulatório de Dermatologia Sanitária, Porto Alegre, RS, Brasil \\ ${ }^{2}$ Fundação de Dermatologia Tropical e Venerologia Alfredo da Matta, Manaus, AM, Brasil \\ ${ }^{3}$ Secretaria de Estado de Saúde de São Paulo, Programa Estadual de DST/Aids, São Paulo, SP, Brasil \\ ${ }^{4}$ Ministério da Saúde, Secretaria de Vigilância em Saúde, Brasília, DF, Brasil
}

\section{Resumo}

As infecções que causam úlcera genital são um dos temas que compõem o Protocolo Clínico e Diretrizes Terapêuticas para Atenção Integral às Pessoas com Infecções Sexualmente Transmissíveis, publicado pelo Ministério da Saúde do Brasil em 2020. Tal documento foi elaborado com base em evidências científicas e validado em discussões com especialistas. Este artigo aborda a síndrome clínica de úlcera genital causada por infecções sexualmente transmissíveis e seus agentes etiológicos mais comuns: Treponema pallidum (sífilis), vírus herpes simples 2 (herpes genital) e vírus herpes simples 1 (herpes perioral), Haemophilus ducreyi (cancroide), Chlamydia trachomatis sorotipos L1, L2 e L3 (linfogranuloma venéreo) e Klebsiella granulomatis (donovanose). São apresentados aspectos epidemiológicos e clínicos dessas infecções, bem como orientações para seu diagnóstico e tratamento, além de estratégias para as ações de vigilância, prevenção e controle, com a finalidade de subsidiar gestores e profissionais de saúde na qualificação da assistência.

Palavras-chave: Sífilis; Cancro; Herpes Genital; Cancroide; Linfogranuloma Venéreo; Granuloma Inguinal.

Endereço para correspondência:

Leonor Henriette de Lannoy - Ministério da Saúde, Secretaria de Vigilância em Saúde, SRTVN, Quadra 701, Via W 5 Norte, Lote D, Edifício PO 700, Brasília, DF, Brasil. CEP 70719-040

E-mail: leonordelannoy@gmail.com 


\section{Apresentação}

0 presente artigo aborda as infecções que causam úlcera genital, tema que compõe o Protocolo Clínico e Diretrizes Terapêuticas (PCDT) para Atenção Integral às Pessoas com Infecções Sexualmente Transmissíveis (IST), publicado pela Secretaria de Vigilância em Saúde do Ministério da Saúde do Brasil em 2020. ${ }^{1}$ Para a elaboração desse documento, foram realizadas seleção e análise das evidências disponíveis e discussão em painel de especialistas, além da aprovação pela Comissão Nacional de Incorporação de Tecnologias no Sistema Único de Saúde (Conitec). ${ }^{2}$

\section{Aproximadamente $70 \%$ dos casos de úlceras genitais atendidos em clínicas especializadas são decorrentes de infecções sexualmente transmissíveis, particularmente em adolescentes e adultos jovens.}

\section{Aspectos epidemiológicos}

Aproximadamente $70 \%$ dos casos de úlceras genitais atendidos em clínicas especializadas são decorrentes de IST, particularmente em adolescentes e adultos jovens. ${ }^{3}$ Como síndrome, as úlceras genitais não são agravos de notificação compulsória no Brasil, o que dificulta quantificar sua ocorrência. São, no entanto, causa frequente de consultas e constituem significativo cofator para transmissão do vírus da imunodeficiência humana (buman immunodeficiency virus, HIV). ${ }^{4}$ As úlceras genitais podem apresentar diferentes causas, como outras infecções, trauma, doenças inflamatórias (por exemplo, pênfigo, eritema multiforme, dermatite de contato, líquen plano erosivo ou erupção fixa por drogas) e lesões neoplásicas (por exemplo, carcinoma espinocelular ou outras neoplasias). Essas últimas são particularmente importantes em pessoas idosas e com imunodepressão. ${ }^{1}$

0 estabelecimento do agente etiológico em bases clínicas é difícil, devido ao polimorfismo nas apresentações. ${ }^{5}$ A disponibilidade de testes diagnósticos acurados e com resultado rápido varia conforme os diferentes agentes e os distintos cenários nos sistemas de saúde. Por essa razão, a Organização Mundial da
Saúde (OMC) preconizou o tratamento sindrômico, adotado por vários países. $3 ., 6,7$

0 agente mais comumente encontrado em úlceras genitais é o vírus do herpes simples (herpes simplex virus, HSV), em seus tipos 1 e 2. São vírus DNA que pertencem à família Herpesviridae. ${ }^{8} 0$ segundo agente mais comum é o Treponema pallidum, causador da sífilis. Esses agentes podem também ser encontrados em associação. ${ }^{3,9} 0$ Brasil, de forma semelhante a outros países, ${ }^{10}$ enfrenta elevação importante nos casos de sífilis desde 2017. Em 2018, o país apresentou taxa de deteç̧ão de sífilis adquirida de 75,8 casos por 100 mil habitantes. ${ }^{10}$

0 cancroide é causado pelo Haemophilus ducreyi, uma bactéria Gram-negativa de transmissão sexual. A doença, que ocorre com maior frequência em homens e nas regiões tropicais, ${ }^{1,11}$ vem sofrendo significativa redução, possivelmente em decorrência da introdução da abordagem sindrômica. ${ }^{12}$ Em revisão sistemática realizada com publicações no período de 1980 a 2014, observou-se que, após o ano 2000, até $15 \%$ das úlceras genitais eram cancroide, com 14 estudos realizados em 13 países. ${ }^{6}$ Desde 0 ano 2000, os casos de cancroide são esporádicos na Europa. ${ }^{11}$ Em estudo brasileiro, realizado em centro especializado de IST em Manaus, não foi identificado nenhum caso de cancroide em 434 úlceras genitais analisadas consecutivamente sem seleção prévia?

0 linfogranuloma venéreo é causado pela Chlamydia trachomatis, sorotipos L1, L2 e L3, que são altamente invasivos. A transmissão é também atribuída a pessoas assintomáticas. ${ }^{13,14}$ É doença endêmica entre homens que fazem sexo com homens (HSH) na Europa, predominantemente infecções anogenitais e retais. ${ }^{14}$ Surtos de linfogranuloma venéreo em países de alta renda, também entre HSH (principalmente pela variante $\mathrm{L} 2 \mathrm{~b}$ ), foram associados à exposição anal receptiva sem proteção e à infecção com HIV. ${ }^{15}$ Acredita-se que a atividade sexual facilitada por viagens globais, redes sociais on-line e a profilaxia pré-exposição da infecção pelo HIV têm contribuído para sua reemergência. ${ }^{15}$

A donovanose é causada pela Klebsiella granulomatis, sendo uma doença muito rara, mais encontrada em países de climas tropicais e subtropicais. Associada à transmissão sexual, possui transmissibilidade baixa e seus mecanismos de transmissão não são bem conhecidos. ${ }^{16}$ 


\section{Aspectos clínicos}

Os aspectos clínicos das úlceras genitais são bastante variados e têm baixa relação de sensibilidade e especificidade com 0 agente etiológico. ${ }^{9} 0$ diagnóstico com base na impressão clínica apresentou valores preditivos positivos de 30,9\% para sífilis e 32,7\% para cancroide, sem correlação clínica para casos com cancro misto no Brasil. ${ }^{9}$ Ainda assim, as características das úlceras genitais devem ser avaliadas e variam conforme 0 agente etiológico.

\section{Vírus do herpes simples 1 e 2}

A infecção pelo HSV 1 e 2, por vezes, apresenta-se como primoinfecção sintomática, que ocorre com uma incubação de seis dias em média e uma duração aproximada de 20 dias. ${ }^{8,17,18}$ É caracterizada por numerosas vesículas que evoluem para lesões ulceradas, dolorosas, cujos fundos apresentam-se recobertos por um induto amarelado. São acompanhadas de mal-estar geral, febre, mialgia, linfadenomegalia regional dolorosa e severos sintomas urinários, especialmente em mulheres. ${ }^{18}$

Ocorrida a infecção, o vírus é transportado ao longo dos axônios dos nervos periféricos para gânglios sensitivos e entra em latência, estado em que pode persistir por toda a vida ou sofrer reativações. Reativado, 0 vírus migra para as superfícies mucosa e cutânea, novamente pelos nervos sensoriais, podendo ser eliminado de forma assintomática ou causar episódios de lesões recorrentes. Os surtos, que podem eventualmente ser a primeira manifestação, são espontâneos ou induzidos por vários fatores (por exemplo, exposição à radiação ultravioleta, infecções, uso de medicamentos, imunodeficiência ou estresse físico ou emocional). Manifestações recorrentes são mais frequentes pelo HSV-2 em comparação com o HSV-1. ${ }^{17}$ A maioria dos indivíduos infectados apresentará recorrências em período menor que um ano, e a cada ano subsequente, sua intensidade e número médio diminuem em cerca de um evento por ano. Essas recorrências são mais leves e apresentam menor duração. São frequentemente precedidas por sinais prodrômicos identificados pelo indivíduo, como prurido, parestesia ou dor no local de surgimento das lesões, na proximidade da região de ocorrência da primoinfecção. Inicialmente, são vesículas de conteúdo citrino agrupadas em cachos sobre uma base eritematosa. As vesículas raramente são encontradas nas mucosas, pois se rompem mais rapidamente, e originam úlceras policíclicas que regridem espontaneamente em aproximadamente sete a dez dias. ${ }^{17,18}$

\section{Sifilis}

Doença crônica transmitida pelo contato sexual, seja genital, anal ou oral, ou, ainda, por transmissão vertical. ${ }^{1,19,20}$ Alterna períodos de latência e manifestações clínicas, frequentemente lesões cutaneomucosas, e pode acometer qualquer órgão com manifestações transitórias ou definitivas, a depender do órgão acometido. ${ }^{13} \mathrm{~A}$ úlcera genital clássica, denominada cancro duro, ocorre tipicamente como úlcera única e indolor, com fundo limpo e base infiltrada, ocorrendo no local de entrada do T. pallidum. ${ }^{9,20}$ Mais comum nos órgãos genitais, a úlcera pode passar despercebida, principalmente quando localizada em cavidades, como interior da vagina, regiões perianal e retal e cavidade oral. 0 período de incubação é de dez a 90 dias, com média de três semanas. 0 cancro duro desaparece sem cicatriz, com ou sem tratamento, em aproximadamente três a oito semanas. Tipicamente é acompanhado de aumento dos linfonodos regionais, mais frequentemente unilaterais, em geral múltiplos, sendo que um se destaca pelo maior tamanho. São indolores, de consistência elástica e não supurativos. ${ }^{1,20,21}$

\section{Cancroide}

0 cancro mole ou cancro de Ducrey é tipicamente caracterizado por úlceras genitais ou perianais muito dolorosas. Raramente ocorre na cavidade oral ou outras regiões do tegumento. Possui borda irregular e fundo sujo, recoberto por induto amarelado, necrótico e fétido. Quando removido, revela tecido de granulação friável e de base não infiltrada. As localizações mais frequentes, no homem, são o frênulo e o sulco bálano-prepucial, e na mulher, a fúrcula e a face interna dos pequenos e grandes lábios. ${ }^{12}$ Lesões satélites por autoinoculação são comuns, assim como cicatrizes desfigurantes. É acompanhado de adenite inguinal em $30 \%$ a $50 \%$ dos casos, um bubão inflamatório unilateral que tende a fistulizar por um único orifício. Linfonodos tensos e com flutuação podem ser aliviados por aspiração com agulha. A drenagem ou excisão dos linfonodos acometidos é contraindicada. Podem acometer cadeias de linfonodos profundos sob a forma de doença sistêmica. ${ }^{11}$ 


\section{Linfogranuloma venéreo}

Apresenta úlcera que geralmente passa despercebida pela pessoa infectada ou pelo profissional de saúde. Sua evolução ocorre em três fases: inoculação, disseminação linfática regional e sequela.

A fase de inoculação inicia-se por pápula, pústula ou pequena úlcera indolor, que desaparece sem deixar sequela. Pode ocorrer no reto e raramente na uretra ou no colo do útero. Dependendo de sua localização, pode apresentar exsudato mucopurulento..$^{14,22} \mathrm{~A}$ fase de disseminação linfática regional desenvolve-se entre uma e seis semanas após a infecção. Em especial na mulher, a cadeia ganglionar acometida depende da localização da lesão inicial. No homem, a linfadenopatia inguinal representa o principal motivo de consulta e é unilateral em $70 \%$ dos casos. ${ }^{14,22} \mathrm{Na}$ última fase clínica da doença, chamada fase de sequela, o comprometimento dos gânglios evolui com fusão de linfonodos em uma grande massa, com liquefação e fistulização por orifícios múltiplos. 0 contato orogenital pode causar glossite ulcerativa com linfadenopatia regional. Pode cursar com proctite ou proctocolite, simulando, por vezes, câncer de reto. A doença pode ser acompanhada de sintomas gerais, como febre, mal-estar, anorexia, emagrecimento, artralgia, sudorese noturna e meningismo. Em caso de lesões iniciais no colo uterino ou no fundo de saco vaginal, a drenagem linfática é realizada por gânglios pararretais, com dano permanente da rede linfática. A obstrução linfática crônica leva à elefantíase genital, que, na mulher, é denominada estiomene. Podem ocorrer fístulas retais, vaginais ou vesicais, assim como estenose orificial, eventos que devem sempre sugerir o diagnóstico de linfogranuloma venéreo. ${ }^{14,22}$

\section{Donovanose}

A lesão inicial pode ter aspectos variados. Pode iniciar-se com uma úlcera de borda plana que evolui para uma úlcera hipertrófica ou vegetante, com fundo granuloso, sendo única ou múltipla, bem delimitada, que evolui lenta e progressivamente. Tem aspecto vermelho vivo e fácil sangramento à manipulação. Há predileção pelas dobras cutâneas ou mucosas, com frequente "configuração em espelho". ${ }^{23}$ Não ocorre adenite, mas podem surgir pseudobubões na região inguinal (nódulos granulomatosos subcutâneos). A elefantíase genital é uma sequela tardia por fenômenos obstrutivos linfáticos. A disseminação extragenital é rara e, na maior parte das vezes, ocorre a partir de lesões genitais ou perigenitais primárias. ${ }^{16,23} 0$ diagnóstico diferencial da donovanose inclui sífilis, cancroide, tuberculose e outras doenças granulomatosas, amebíase cutânea, neoplasias ulceradas e leishmaniose tegumentar americana. ${ }^{1,16}$

\section{Diagnóstico}

0 atendimento de pessoas com lesões apresenta particularidades. A entrevista deve ser realizada em ambiente de privacidade, de forma empática e sem juízo de valores, seja por meio de discurso ou linguagem não verbal. Deve incluir indagações sobre práticas sexuais e identificação de fatores de risco para IST, como: idade abaixo de 30 anos; história de novas ou múltiplas parcerias sexuais, especialmente nos últimos três meses; parcerias sexuais com IST, IST prévias ou concomitantes; e utilização irregular de preservativos. ${ }^{9,24,25}$ Drogas psicoativas, encontros sexuais anônimos ou grupais, atividade sexual profissional, abuso sexual, situação de rua ou privação de liberdade devem ser considerados. Populações com dificuldade de acesso aos serviços, como pessoas transexuais, merecem especial atenção.

0 diagnóstico etiológico de úlceras genitais baseado em anamnese e exame físico pode ser impreciso; por isso, é importante a utilização de testes diagnósticos sempre que disponíveis. ${ }^{9,26}$ Esses exames, no entanto, só possuem valor no caso de os resultados estarem disponíveis de forma imediata, pois a instituição de tratamento não deve ser postergada em função dos resultados. A sensibilidade desses exames é variável em virtude de particularidades técnicas e depende da quantidade de patógenos na amostra obtida. ${ }^{9,27}$

\section{Vírus do herpes simples tipos 1 e 2}

Estão disponíveis testes sorológicos para deteç̧ão do HSV 1 e 2. Apesar de esses testes pouco auxiliarem no diagnóstico, a identificação do tipo viral pode ser útil na avaliação de prognóstico e aconselhamento. Estima-se que $0 \mathrm{HSV}-2$ tenha maior transmissibilidade, incluindo a transmissão da gestante para o recém-nascido.,24

A cultura viral, reservada para ambientes de pesquisa e considerada exame padrão ouro, vem sendo substituída por testes que se baseiam na amplificação de ácidos nucleicos (nucleic acid amplification test, NAAT), os quais possuem maior sensibilidade e praticidade. ${ }^{26}$ 


\section{Treponema pallidum}

A microscopia em campo escuro pode permitir a identificação de espiroquetas com forma e movimentos característicos. Utiliza-se linfa obtida pela expressão, idealmente sem sangramento, que deve ser analisada imediatamente. A utilização de material obtido em lesões da cavidade oral é inapropriada, devido à presença de espiroquetas saprófitas não relacionadas à sífilis. A imunofluorescência direta ou colorações especiais necessitam processamento mais longo e dificilmente serão úteis no contexto clínico. A identificação de lesão genital indica investigação sorológica para esclarecimento diagnóstico e rastreamento de IST concomitantes. Existem dois tipos de testes sorológicos, os treponêmicos e os não treponêmicos. Entre os testes treponêmicos, podem ser citados: testes rápidos por imunocromatografia, fluorescent treponemal antibody-absorption (FTAAbs), T. pallidum particle agglutination assay (TPHA), eletroquimioluminescência e 0 ensaio de imunoabsorção enzimática (enzyme-linked immunossorbent assay, ELISA). Os testes não treponêmicos, como o venereal disease research laboratory (VDRL) e rapid plasma reagin (RPR), possuem particular importância no seguimento sorológico. ${ }^{19,20,26}$ Os testes treponêmicos tornam-se positivos, em média, de uma a três semanas do início da lesão, pouco mais precocemente do que os não treponêmicos. Os testes rápidos, distribuídos pelo Ministério da Saúde, são práticos, seguros e de fácil execução por profissional treinado. Fornecem resultado em até 30 minutos e permitem suporte diagnóstico, tomada de decisão no momento da consulta e tratamento imediato. ${ }^{27}$

\section{Haemophilus ducreyi}

A microscopia de esfregaços obtidos de lesões com exsudato abundante pode permitir a identificação de estreptobacilos organizados dois a dois, configuração comparada a "trilhos de trem". Esse exame tem sensibilidade e especificidade bastante inferiores em relação à cultura, a qual, no entanto, é um procedimento com muitas exigências e de difícil execução. As técnicas de amplificação de DNA, como NAAT, passaram a ser consideradas o padrão ouro para a deteç̧ão do $H$. ducreyi, com sensibilidade de até 98,4\%. Alguns kits para reação em cadeia da polimerase (polymerase chain reaction, PCR) têm a vantagem de testar simultaneamente outros agentes, como T. pallidum e HSV., ${ }^{911,12,26}$

\section{Chlamydia trachomatis}

Os testes NAAT, que incluem PCR e reação em cadeia da ligase, são os métodos recomendados para detecção de $C$. trachomatis em material colhido de espécimes de úlcera, reto, aspirados de bubão, faringe, espécimes de biópsia e amostras de urina, pouco disponíveis na rotina. ${ }^{14,21,28} 0$ s testes sorológicos apresentam pouca importância para a identificação de $C$. trachomatis., ${ }^{9,26}$

\section{Klebsiella granulomatis}

0 diagnóstico pode ser estabelecido pela identificação dos corpúsculos de Donovan na microscopia de esfregaços de fragmentos teciduais ou seu estudo anatomopatológico, corados pelos métodos de Giemsa, Leishman, Wright ou Rapi-Diffi. É um microrganismo de difícil cultura e os NAAT estão disponíveis, especialmente em instituições de pesquisa. ${ }^{9116,26,29}$

\section{Tratamento}

As IST são a principal causa de úlceras genitais e devem invariavelmente compor as hipóteses diagnósticas, em especial na presença de elementos epidemiológicos. Úlceras de evolução mais longa, de mais de quatro semanas, requerem avaliação mais cuidadosa, uma vez que podem estar relacionadas a processos neoplásicos, doenças infecciosas crônicas ou imunossupressão. Na maioria das vezes, esses processos requerem atendimento especializado, realização de biópsia e estudos histopatológicos.

A importância das IST como questão de saúde pública reside na sua elevada frequência de ocorrência e na necessidade de interromper a transmissão. A utilização de exames laboratoriais, ainda que desejável, apresenta limitações. Em caso de úlcera genital com suspeita de IST, não é aceitável retardar o tratamento em função dos resultados de exames laboratoriais. A utilização de combinações de opções terapêuticas, visando ao tratamento de um ou mais agentes, é desejável em alguns cenários. ${ }^{91,19,20,24,25,30}$

A Figura 1 apresenta orientações para 0 manejo de infecções que causam úlceras genitais. ${ }^{1} \mathrm{Em}$ decorrência da significativa redução da incidência do cancroide, ${ }^{7}$ da falta de vigilância epidemiológica desse agravo ${ }^{31}$ e da constante necessidade de atualização das recomendações, o Ministério da Saúde instituiu, 


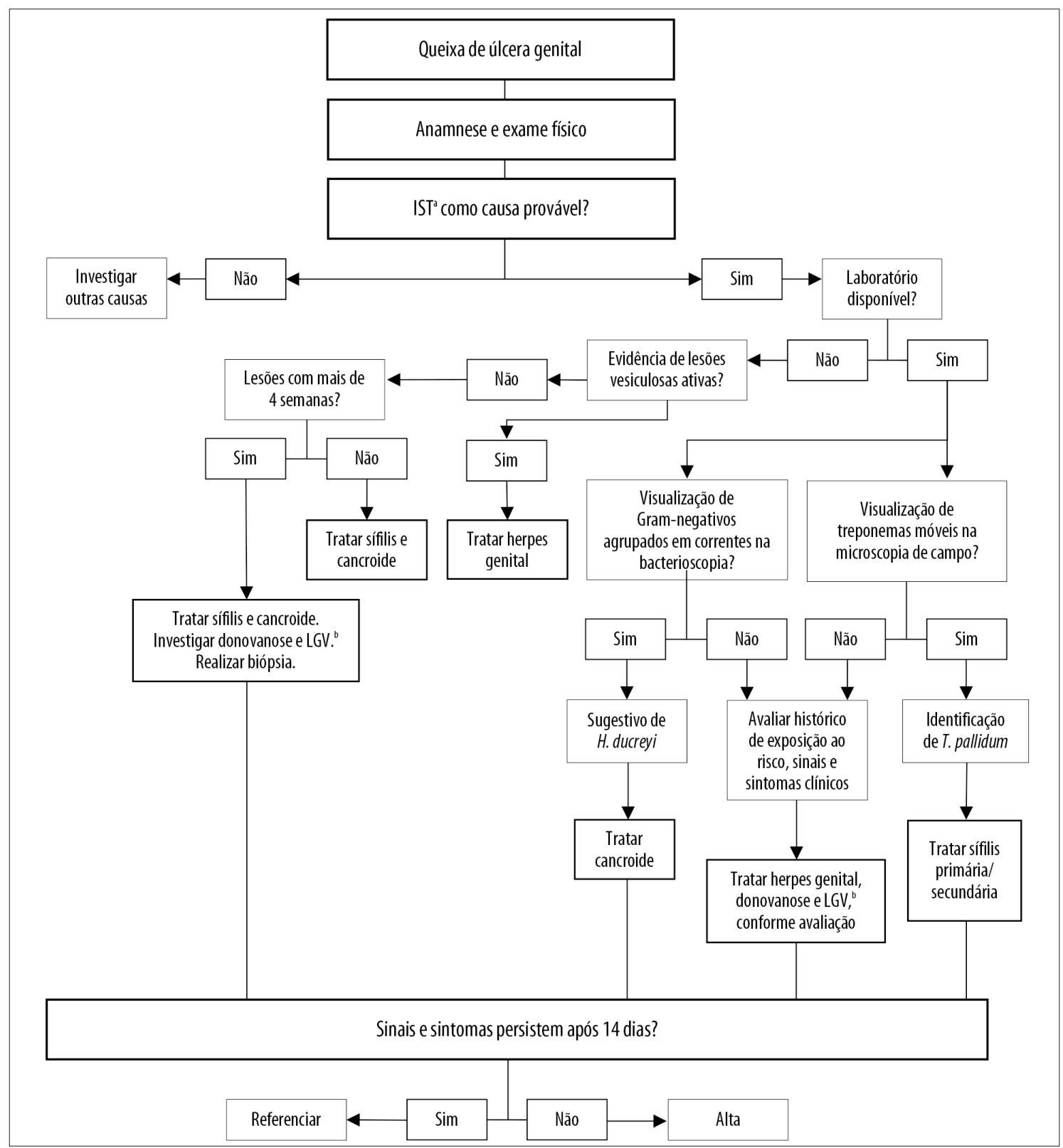

Fonte: adaptado do Protocolo Clínico e Diretrizes Terapêuticas para Atenção Integral às Pessoas com Infecções Sexualmente Transmissíveis, 2020. Notas: a) IST: infecções sexualmente transmissíveis; b) LGV: linfogranuloma venéreo.

\section{Figura 1 - Recomendações para manejo de infecções que causam úlcera genital}

em 2018, projeto para identificar os principais agentes etiológicos das úlceras genitais (HSV tipo 1 e 2, T. pallidum e $H$. ducreyi) utilizando testes moleculares em serviços específicos. Os achados desse projeto poderão modificar 0 atual fluxograma de conduta frente às úlceras genitais, a exemplo do que ocorreu com a síndrome do corrimento uretral. . $233^{33}$
Durante a avaliação de queixa de úlcera genital, diante da evidência ou história de lesões vesiculosas características, é indicado o tratamento de herpes genital. Caso se trate do primeiro episódio, deve-se prescrever aciclovir $200 \mathrm{mg}$, dois comprimidos, via oral, três vezes ao dia, por sete a dez dias, e, em caso de recidiva, aciclovir $200 \mathrm{mg}$, dois comprimidos, 
via oral, três vezes ao dia, por cinco dias. Em casos de necessidade de supressão de herpes genital (seis ou mais episódios por ano), deve-se utilizar aciclovir $200 \mathrm{mg}$, dois comprimidos, via oral, duas vezes ao dia, por até seis meses, com possibilidade de prolongar o tratamento por até dois anos.

No caso do tratamento das demais IST que cursam com úlceras genitais e quadros com menos de quatro semanas de evolução, deve-se tratar sífilis (cancro duro) com penicilina benzatina, dose única de 2,4 milhões de unidades internacionais (UI), intramuscular profundo (1,2 milhão UI em cada glúteo), e cancroide com azitromicina $1 \mathrm{~g}$, dose única, via oral. Nos casos de lesões com mais de quatro semanas de evolução, deve-se realizar biópsia e avaliar a instituição do tratamento de sífilis, cancroide, linfogranuloma venéreo e donovanose. Para o linfogranuloma venéreo e donovanose, são necessários tratamentos mais prolongados. No caso de linfogranuloma, deve-se usar doxiciclina $100 \mathrm{mg}$, via oral, duas vezes por dia, durante 21 dias, como primeira opção, e azitromicina como alternativa. No caso de donavonose, recomenda-se usar como primeira opção azitromicina $500 \mathrm{mg}$, dois comprimidos, via oral, uma vez por semana, por pelo menos três semanas ou até a cicatrização das lesões, e, como tratamento alternativo, pode ser avaliado o uso de doxiciclina, ciprofloxacino ou sulfametoxazol-trimetropina. ${ }^{1}$ Os tratamentos recomendados, inclusive em situações especiais como imunossupressão e gestação, estão sintetizados nas Figuras 2 e 3. É importante destacar que, diante de lesão de evolução súbita e com história de exposição a fármacos, deve ser considerada a erupção fixa por drogas. ${ }^{24,34}$

As parcerias sexuais dos últimos três meses devem ser orientadas quanto aos riscos de exposição, além de avaliadas e tratadas conforme achados clínicos, laboratoriais ou epidemiológicos. $8,9,12,24,25$ Devem-se avaliar as parcerias sexuais de indivíduos com sífilis cuja exposição ocorreu até 90 dias antes do início de sintomas, ${ }^{19,20}$ realizando seu tratamento presuntivo com dose única de penicilina benzatina 2,4 milhões UI, dose única, intramuscular. As parcerias sexuais de indivíduos com cancroide cuja exposição ocorreu até dez dias antes de início de sintomas devem ser avaliadas e tratadas com azitromicina $500 \mathrm{mg}$, dois comprimidos, via oral, dose única. ${ }^{9,12}$ Para as parcerias assintomáticas de pessoas

\begin{tabular}{|c|c|c|}
\hline Condição clínica & Tratamento & Comentários \\
\hline \multirow[b]{2}{*}{ Primeiro episódio } & \multirow{2}{*}{$\begin{array}{l}\text { Aciclovir } 200 \mathrm{mg}, 2 \text { comprimidos, via oral (V0), } \\
3 \mathrm{x} / \text { dia, por } 7-10 \text { dias ou aciclovir } 200 \mathrm{mg}, 1 \\
\text { comprimido, V0, } 5 \mathrm{x} / \text { dia }(7 \mathrm{~h}, 11 \mathrm{~h}, 15 \mathrm{~h}, 19 \mathrm{~h}, 23 \mathrm{~h} \text {, } \\
\text { 7h), por 7-10 dias }\end{array}$} & Iniciar o tratamento o mais precocemente possível. ${ }^{b}$ \\
\hline & & $\begin{array}{l}0 \text { tratamento pode ser prolongado se a cicatrização estiver } \\
\text { incompleta após } 10 \text { dias de terapia. }{ }^{.}\end{array}$ \\
\hline Recidiva & $\begin{array}{l}\text { Aciclovir } 200 \mathrm{mg}, 2 \text { comprimidos, V0, } 3 \mathrm{x} / \text { dia, por } \\
5 \text { dias ou Aciclovir } 200 \mathrm{mg}, 4 \text { comprimidos, V0, } \\
2 \mathrm{x} / \text { dia, por } 5 \text { dias }\end{array}$ & $\begin{array}{l}0 \text { tratamento deve ser iniciado preferencialmente no período } \\
\text { prodrômico (aumento de sensibilidade local, ardor, dor, prurido e } \\
\text { hiperemia da região genital). }{ }^{\mathrm{b}, \mathrm{c}}\end{array}$ \\
\hline \multirow{2}{*}{$\begin{array}{l}\text { Supressão de herpes genital } \\
\text { ( } 6 \text { ou mais episódios/ano) }\end{array}$} & \multirow{2}{*}{$\begin{array}{l}\text { Aciclovira } 200 \mathrm{mg}, 2 \text { comprimidos, } \mathrm{V} 0,2 \mathrm{x} / \mathrm{dia} \text {, } \\
\text { por até } 6 \text { meses, podendo o tratamento ser } \\
\text { prolongado por até } 2 \text { anos }\end{array}$} & $\begin{array}{l}\text { Consideram-se elegíveis para o tratamento supressivo indivíduos } \\
\text { com episódios repetidos de herpes genital (mais de } 6 \text { ao ano). }\end{array}$ \\
\hline & & Indicada avaliação periódica de função renal e hepática. ${ }^{\mathrm{b}, \mathrm{c}}$ \\
\hline $\begin{array}{l}\text { Herpes genital em } \\
\text { imunossuprimidos }\end{array}$ & $\begin{array}{l}\text { Aciclovira endovenoso, } 5-10 \mathrm{mg} / \mathrm{kg} \text { de peso, de } \\
\text { 8/8h, por } 5 \text { a } 7 \text { dias, ou até resolução clínica }\end{array}$ & $\begin{array}{l}\text { Em caso de lesões extensas em indivíduos com imunossupressão } \\
\text { (usuários crônicos de corticoide, pessoas em uso de } \\
\text { imunomoduladores, transplantados de órgãos sólidos e pessoas } \\
\text { vivendo com HIV), pode-se optar pelo tratamento endovenoso., }\end{array}$ \\
\hline \multirow[b]{2}{*}{ Gestação } & \multicolumn{2}{|c|}{ Tratar o primeiro episódio em qualquer trimestre da gestação, conforme o tratamento para o primeiro episódio. } \\
\hline & \multicolumn{2}{|c|}{$\begin{array}{l}\text { Se a primoinfecção ocorreu na gestação ou se recidivas foram frequentes no período gestacional, pode-se realizar } \\
\text { terapia supressiva, a partir da } 36^{\mathrm{a}} \text { semana, com aciclovir } 400 \mathrm{mg}, 3 \mathrm{x} / \mathrm{dia} \text {. }\end{array}$} \\
\hline
\end{tabular}

Fonte: adaptado do Protocolo Clínico e Diretrizes Terapêuticas para Atenção Integral às Pessoas com Infecções Sexualmente Transmissíveis, 2020.

Notas: a) 0 tratamento com antivirais é eficaz para redução da intensidade e duração dos episódios, quando realizado precocemente; b) 0 tratamento local pode ser feito com compressas de solução fisiológica ou degermante em solução aquosa, para higienização das lesões. Analgésicos orais podem ser utilizados, se necessário. É recomendado retorno em uma semana para reavaliação das lesões; c) A forma de transmissão, a possibilidade de infecção assintomática, o medo de rejeição por parte das parcerias sexuais e as preocupaçães sobre a capacidade de ter filhos são aspectos que devem ser abordados. É importante mencionar que não há associação entre herpes simples genital e câncer.

\section{Figura 2 - Tratamento de herpes genital}




\begin{tabular}{|c|c|c|c|}
\hline $\begin{array}{l}\text { Infecção sexualmente } \\
\text { transmissível }\end{array}$ & Primeira opção & Alternativa & Comentários \\
\hline \multirow[b]{2}{*}{ Sífilis (cancro duro) } & \multirow{2}{*}{$\begin{array}{l}\text { Benzilpenicilina benzatina } \\
2,4 \text { milhões de unidades } \\
\text { internacionais (UI), } \\
\text { intramuscular (IM), dose } \\
\text { única (1,2 milhão Ul em cada } \\
\text { glúteo) }\end{array}$} & \multirow[b]{2}{*}{$\begin{array}{l}\text { Doxiciclina } 100 \mathrm{mg}, 12 / 12 \mathrm{~h} \text {, via } \\
\text { oral (V0), por } 15 \text { dias }\end{array}$} & $\begin{array}{l}\text { Tratamento para sífilis recente: sífilis primária, } \\
\text { secundária e latente recente (com até um ano de } \\
\text { evolução). }\end{array}$ \\
\hline & & & $\begin{array}{l}\text { Se considerada sífilis tardia: tratar com } \\
\text { benzilpenicilina benzatina 2,4 milhões UI, IM, } \\
\text { semanal ( } 1,2 \text { milhão UI em cada glúteo), por } \\
3 \text { semanas (dose total: } 7,2 \text { milhões UI, IM). } \\
\text { Alternativa: doxiciclinaa 100mg, 12/12h, V0, por } \\
30 \text { dias. }\end{array}$ \\
\hline \multirow{3}{*}{ Cancroide } & \multirow{3}{*}{$\begin{array}{l}\text { Azitromicina 500mg, } 2 \\
\text { comprimidos, V0, dose única }\end{array}$} & \multirow{3}{*}{$\begin{array}{l}\text { Ceftriaxona } 250 \mathrm{mg} \text {, IM, dose } \\
\text { única ou ciprofloxacino b } 500 \mathrm{mg}, 1 \\
\text { comprimido, V0, 2x/dia, por } 3 \text { dias }\end{array}$} & $\begin{array}{l}0 \text { tratamento sistêmico deve ser acompanhado de } \\
\text { medidas locais de higiene. }\end{array}$ \\
\hline & & & $\begin{array}{l}0 \text { prolongamento da terapia pode ser necessário } \\
\text { até a resolução da sintomatologia. }\end{array}$ \\
\hline & & & $\begin{array}{l}\text { A antibioticoterapia não tem efeito expressivo } \\
\text { na duração da linfadenopatia inguinal, mas os } \\
\text { sintomas agudos são frequentemente erradicados } \\
\text { de modo rápido. }\end{array}$ \\
\hline Linfogranuloma venéreo & $\begin{array}{l}\text { Doxiciclina }{ }^{\mathrm{a}} \text { 100mg, V0, } 1 \\
\text { comprimido, 2x/dia, por } 21 \\
\text { dias }\end{array}$ & $\begin{array}{l}\text { Azitromicina 500mg, } 2 \\
\text { comprimidos, V0, 1x/semana, } \\
\text { por } 21 \text { dias (preferencial nas } \\
\text { gestantes) }\end{array}$ & $\begin{array}{l}\text { Os antibióticos não revertem sequelas como } \\
\text { estenose retal ou elefantíase genital. }\end{array}$ \\
\hline \multirow{3}{*}{ Donovanose } & \multirow{3}{*}{$\begin{array}{l}\text { Azitromicina } 500 \mathrm{mg}, 2 \\
\text { comprimidos, } \mathrm{V} 0,1 \mathrm{x} / \mathrm{semana}, \\
\text { por pelo menos três semanas, } \\
\text { ou até a cicatrização das lesões }\end{array}$} & \multirow{3}{*}{$\begin{array}{l}\text { Doxiciclina } 100 \mathrm{mg}, 1 \text { comprimido, } \\
\text { V0, } 2 x / \text { dia, por pelo menos } 21 \\
\text { dias, ou até o desaparecimento } \\
\text { completo das lesões ou } \\
\text { ciprofloxacino } 500 \mathrm{mg}, 1 \text { e } 1 / 2 \\
\text { comprimido, V0, } 2 x / \text { dia, por } \\
\text { pelo menos } 21 \text { dias, ou até a } \\
\text { cicatrização das lesões (dose } \\
\text { total: } 750 \mathrm{mg} \text { ) ou sulfametoxazol- } \\
\text { trimetoprima ( } 400 / 80 \mathrm{mg}), 2 \\
\text { comprimidos, V0, } 2 x / \text { dia, por } \\
\text { no mínimo } 3 \text { semanas, ou até a } \\
\text { cicatrização das lesões }\end{array}$} & $\begin{array}{l}\text { Não havendo resposta na aparência da lesão nos } \\
\text { primeiros dias de tratamento com ciprofloxacino, } \\
\text { recomenda-se adicionar um aminoglicosídeo, } \\
\text { como a gentamicina, } 1 \mathrm{mg} / \mathrm{kg} / \text { dia, endovenoso, } \\
3 x / \text { dia, por pelo menos três semanas, ou até } \\
\text { cicatrização das lesões. }\end{array}$ \\
\hline & & & $\begin{array}{l}\text { Em pessoas vivendo com HIV, sugerem-se } \\
\text { os mesmos esquemas terapêuticos; } 0 \text { uso de } \\
\text { terapia parenteral com a gentamicina deve ser } \\
\text { considerado nos casos mais graves. }\end{array}$ \\
\hline & & & $\begin{array}{l}\text { As sequelas da destruição tecidual ou obstrução } \\
\text { linfática podem exigir correção cirúrgica. }\end{array}$ \\
\hline
\end{tabular}

Fonte: adaptado do Protocolo Clínico e Diretrizes Terapêuticas para Atenção Integral às Pessoas com Infecções Sexualmente Transmissíveis, 2020' e diretrizes do CDC, $2015 .{ }^{9}$ Notas: a) Doxiciclina está contraindicada para gestantes e lactantes; b) Ciprofloxacino está contraindicado para gestantes, lactantes e crianças.

Figura 3 - Tratamento de úlceras genitais com diagnóstico de sífilis, cancroide, linfogranuloma venéreo ou donovanose

com HSV-1 e HSV-2, não é recomendado tratamento presuntivo. ${ }^{8,31,35}$ Indica-se tratamento presuntivo de parcerias sexuais de pessoas com clamídia, com exposição até 60 dias antes de início de sintomas, 9,14,22,28 com azitromicina $500 \mathrm{mg}$, dois comprimidos, via oral, dose única ou doxiciclina $100 \mathrm{mg}$, um comprimido via oral, duas vezes ao dia por sete dias (contraindicada em gestantes, lactantes e menores de 9 anos). Em caso de donovanose, não é recomendado tratamento presuntivo de parcerias sexuais assintomáticas, pela baixa infectividade. ${ }^{16,29}$

\section{Vigilância, prevenção e controle}

0 aconselhamento centrado na pessoa e suas práticas sexuais objetiva 0 reconhecimento das práticas de maior risco e o estabelecimento de um plano de redução de risco à luz das recomendações da prevenção combinada para IST, HIV e hepatites virais. ${ }^{1}$ Deve-se indicar o uso de métodos de barreira durante a atividade sexual oral, vaginal e anal. Acessórios sexuais devem ser de uso individual e higienizados antes e depois de uso., ${ }^{1,9}$ Deve-se ofertar profilaxia 
da infecção pelo HIV em pós-exposição ou em pré-exposição, quando indicado. ${ }^{1}$

Testes rápidos para detecção da infecção pelo HIV, sífilis e hepatites B e C devem invariavelmente ser recomendados. Testes sorológicos de seguimento pós-terapêuticos são indicados para pessoas com sífilis. $A$ vacinação para profilaxia do HPV e das hepatites A e B deve seguir as recomendações. ${ }^{9,24,25} 0$ rastreamento de infecções por $C$. trachomatis e Neisseria gonorrboeae por NAAT em amostras de urina, exsudato uretral ou cervical é recomendado, em que pese sua indisponibilidade na rotina da maioria dos serviços. ${ }^{1}$

Os casos de sífilis com úlcera que apresentarem um teste reagente (treponêmico ou não treponêmico) devem ser notificados compulsoriamente como sífilis adquirida, ${ }^{31}$ e os parceiros somente serão notificados após a investigação, a depender de resultado de exames e presença de sintomas, conforme definição de caso de sífilis adquirida. ${ }^{1}$

\section{Populações especiais}

\section{Gestantes}

Úlceras genitais por IST merecem atenção cuidadosa, devido ao potencial de transmissão vertical de alguns de seus agentes etiológicos, em especial o T. pallidum. A suspeição de sífilis na gestante indica tratamento de acordo com o estágio clínico, de forma mandatória, independentemente de resultados laboratoriais. Testes não treponêmicos pós-tratamento devem ser realizados a cada 30 dias., ${ }^{9,20} 0 \mathrm{HSV}$ também apresenta especificidades em seu manejo durante a gestação. Sua ocorrência no final da gestação aumenta o risco de complicações fetais e neonatais. Em situação de presença de lesões em atividade em região genital, há indicação de parto cesáreo., ${ }^{8,36,37}$ É rara a ocorrência de eventos adversos na gestação associados ao cancroide e à donovanose. ${ }^{9}$ No caso da donovanose, existem relatos de casos de transmissão perinatal com acometimento de estruturas otorrinolaringológicas do recém-nato. ${ }^{38-40}$

\section{Pessoas com infecção pelo HIV}

Os regimes de tratamento das IST são os mesmos recomendados para pessoas sem infecção pelo HIV. As úlceras genitais facilitam a transmissão de HIV, aumentando a importância do tratamento precoce, e 0 maior risco mostrou-se especialmente significativo no caso do herpes genital, sífilis e cancroide. ${ }^{9,23,24} \mathrm{~A}$ coinfecção com sífilis pode alterar o curso clínico dessa doença, com manifestações atípicas e agressivas ${ }^{19,20}$ e, na coinfecção com HSV, as lesões podem ser mais dolorosas, atípicas e com maior duração, podendo exigir medicamentos via endovenosa para controle dos sintomas. ${ }^{8,35} 0$ cancroide e o linfogranuloma venéreo devem ser monitorados cuidadosamente, uma vez que podem necessitar de tratamento mais prolongado, devido à maior chance de retardo na resposta ou falha terapêutica. ${ }^{14,21,27}$

\section{Contribuição dos autores}

Ramos MC, Aragon MG e de Lannoy LH contribuíram com a concepção, delineamento e redação do manuscrito. Ramos MC, Sardinha JC e Alencar HDR contribuíram na elaboração dos aspectos clínicos, tratamento e vigilância, prevenção e controle, e revisaram criticamente 0 manuscrito. Todos os autores aprovaram a versão final a ser publicada e são responsáveis por todos os aspectos do trabalho, incluindo a garantia de sua precisão e integridade.

\section{Agradecimento}

Os autores agradecem aos membros do grupo técnico de especialistas responsáveis pela elaboração do PCDT para Atenção Integral às Pessoas com IST em 2020 pela contribuição para a realização deste trabalho.

\section{Referências}

1. Ministério da Saúde (BR). Secretaria de Vigilância em Saúde. Departamento de Doenças de Condições Crônicas e Infecções Sexualmente Transmissíveis. Protocolo clínico e diretrizes terapêuticas para atenção integral às pessoas com infecções sexualmente transmissíveis (IST) [Internet]. Brasília: Ministério da Saúde; 2020 [citado 2020 out 19]. 248 p. Disponível em: http://www.aids.gov.br/pt-br/ pub/2015/protocolo-clinico-e-diretrizes-terapeuticas-para-atencao-integral-pessoas-com-infeccoes 
2. Brasil. Ministério da Saúde. Portaria MS/GM n 42 , de 5 de outubro de 2018. Torna pública a decisão de aprovar o Protocolo Clínico e Diretrizes Terapêuticas para Atenção Integral às Pessoas com Infecções Sexualmente Transmissíveis (IST), no âmbito do Sistema Único de Saúde - SUS [Internet]. Diário Oficial da União, Brasília (DF), 2018 out 8 [citado 2020 jul 31]; Seção 1:88. Disponível em: http:// conitec.gov.br/images/Relatorios/Portaria/2018/ Portaria_SCTIE_N42_05_10_2018.pdf

3. Noda AA, Blanco 0, Correa C, Pérez L, Kourí V, Rodríguez I. Etiology of genital ulcer disease in male patients attending a sexually transmitted diseases clinic: first assessment in Cuba. Sex Transm Dis [Internet]. 2016 Aug [cited 2020 Oct 19]; 43(8):494-7. Available from: https:// doi.org/10.1097/0LQ.0000000000000470

4. World Health Organization - WHO. Report on global sexually transmitted infection surveillance, 2018 [Internet]. Geneva: World Health Organization; 2018 [cited 2020 0ct 19]. Available from: https:/www.who.int/reproductivehealth/ publications/stis-surveillance-2018/en/

5. Moherdaui F, Vuylsteke B, Siqueira LF, Santos Júnior MQ, Jardim ML, Brito AM, et al. Validation of national algorithms for the diagnosis of sexually transmitted diseases in Brazil: results from a multicenter study. Sex Transm Infect. 1998 Jun;74(Suppl 1):S38-43.

6. González-Beiras C, Marks MY, Chen C, Roberts S, Mitjà 0. Epidemiology of Haemophilus ducreyi infections. Emerg Infect Dis [Internet]. 2016 Jan [cited 2020 0ct 19]; 22(1):1-8. Available from: https://dx.doi.org/10.3201\%2Feid2201.150425

7. Naveca FG, Sabidó M, Amaral TAP, Veras EA, Contreras Mejía MC, et al. Etiology of genital ulcer disease in a sexually transmitted infection reference center in Manaus, Brazilian Amazon. PLoS One [Internet]. 2013 [cited 2020 0ct 19]; 8(5):e63953. Available from: https://doi.org/10.1371/journal.pone.0063953

8. Patel R, Kennedy OJ, Clarke E, Geretti A, Nilsen A, Lautenschlager S, et al. 2017 European guidelines for the management of genital herpes. Int J STD AIDS [Internet]. 2017 [cited 2020 0ct 19]; 28(14):1366-79. Available from: https://doi.org/10.1177/0956462417727194

9. Workowski KA. Centers for Disease Control and Prevention - CDC. Sexually transmitted diseases treatment guidelines. Clin Infect Dis [Internet]. 2015 [cited 2020 0ct 19]; 61(Suppl 8):S759-62. Available from: https://doi.org/10.1093/cid/civ7712015

10. Ministério da Saúde (BR). Secretaria de Vigilância em Saúde. Departamento de Doenças de Condições Crônicas e Infecções Sexualmente Transmissíveis. Sífilis | 2019. Bol Epidemiol [Internet]. 2019 out [citado 2020 out 19]; especial. Disponível em: http://www.aids.gov. br/pt-br/pub/2019/boletim-epidemiologico-sifilis-2019

11. Lautenschlager S, Kemp M, Christensen JJ, Mayans MV, Moi H. 2017 European guideline for the management of cancroid. Int J STD AIDS [Internet]. 2017 Mar [cited 2020 0ct 19]; 28(4):324-9. Available from: https://doi.org/10.1177/0956462416687913

12. O'Farrell N, Lazaro N. UK National guideline for the management of Chancroid 2014. Int J STD AIDS [Internet]. 2014 Dec [cited 2020 Oct 19]; 25(14):975-83. Available from: https://doi.org/10.1177/0956462414542988

13. Buder S, Schöfer H, Meyer T, Bremer V, Kohl PK, Skaletz-Rorowski A, Brockmeyer N. Bacterial sexually transmitted infections. J Dtsch Dermatol Ges [Internet]. 2019 Mar [cited 2020 0ct 19]; 17(3):287-315. Available from: https://doi.org/10.1111/ddg.13804

14. Vries HJC, Barbeyrac B, De Vrieze NHN, Viset JD, White JA, Vall-Mayans M, et al. 2019 European guideline on the management of lymphogranuloma venereum. JEADV [Internet]. 2019 [cited 2020 0ct 19]; 33:1821-8. Available from: https://doi.org/10.1111/jdv.15729

15. Williamson DA, Chen MY. Emerging and reemerging sexually transmitted infections. N Engl J Med [Internet]. 2020 [cited 2020 0ct 19]; 382(21):2023-32. Available from: https://doi.org/10.1056/nejmra190719

16. O'Farrell N, Moi H. 2016 European guideline on donovanosis. Int J STD AIDS [Internet]. 2016 Feb [cited 2020 0ct 19]; 27(8):605-7. Available from: https://doi.org/10.1177/0956462416633626

17. Garland SM, Steben M. Genital herpes. Best Pract Res Clin Obstet Gynaecol [Internet]. 2014 [cited 2020 0ct 19]; 28(7):1098-110. Available from: https://doi.org/10.1016/j.bpobgyn.2014.07.015

18. Money D, Steben M. No. 207 - Genital herpes: gynaecological aspects. J Obstet Gynaecol Can [Internet]. 2017 Jul [cited 2020 0ct 19]; 39(7):e105-11. Available from: https://doi.org/10.1016/j.jogc.2017.04.015

19. Kingston M, French P, Higgins S, McQuillan 0, Sukthankar A, Stott C, et al. UK national 
guidelines on the management of syphilis 2015 . Int J STD AIDS [Internet]. 2016 May [cited 2020 0ct 19]; 27(6):421-46. Available from: https://doi.org/10.1177/0956462415624059

20. Janier M, Hegyi V, Dupin N, Unemo M, Tiplica GS, Potočnik M, et al. 2014 European guideline on the management of syphilis. J Eur Acad Dermatol Venereol [Internet]. 2014 Dec [cited 2020 0ct 19]; 28(12):158193. Available from: https://doi.org/10.1111/jdv.12734

21. Belda JW, Di Chiacchio N, Criado PR. Tratado de dermatologia. 2. ed. São Paulo: Atheneu; 2015. 2768p.

22. Stoner BP, Cohen SE. Lymphogranuloma venereum 2015: clinical presentation, diagnosis, and treatment. Clin Infect Dis [Internet]. 2015 Dec [cited 2020 0ct 19]; 61(Suppl 8):S865-73. Available from: https://doi.org/10.1093/cid/civ756

23. Velho PE, Souza EM, Belda Junior W. Donovanosis. Braz J Infect Dis [Internet]. 2008 [cited 2020 Oct 19]; 12(6):521-5. Available from: https:// doi.org/10.1590/s1413-86702008000600015

24. Gabrielson AT, Le TV, Fontenot C, Usta M, Hellstrom WJG. Male genital dermatology: a primer for the sexual medicine physician. Sex Med Rev [Internet]. 2019 Jan [cited 2020 0ct 19]; 7(1):71-83. Available from: https://doi.org/10.1016/j.sxmr.2018.09.004

25. Wagenlehner FME, Brockmeyer NH, Discher T, Friese K, Wichelhaus TA. The presentation, diagnosis, and treatment of sexually transmitted infections. Dtsch Arztebl Int [Internet]. 2016 [cited 2020 0ct 19]; 113(1-2):11-22. Available from: https://doi.org/10.3238/arztebl.2016.0011

26. World Health Organization - WHO. Diagnóstico laboratorial de doenças sexualmente transmissíveis, incluindo 0 vírus da imunodeficiência humana [Internet]. Brasília: Organização Mundial da Saúde; Ministério da Saúde; 2013 [citado 2020 out 19]. Disponível em: https://apps.who.int/iris/ bitstream/handle/10665/85343/9789241505840 por.pdf?sequence $=7$

27. Ministério da Saúde (BR). Secretaria de Vigilância em Saúde. Departamento de Vigilância, Prevenção e Controle das Doenças Sexualmente Transmissiveis, HIV/Aids e Hepatites Virais. Manual para o diagnóstico da sífilis [Internet]. Brasília: Ministério da Saúde; 2016 [citado 2020 out 19]. Disponível em: http://www.aids.gov.br/pt-br/pub/2016/ manual-tecnico-para-diagnostico-da-sifilis
28. White J, O'Farrell N, Daniels D. 2013 UK National guideline for the management of lymphogranuloma venereum. Int J STD AIDS [Internet]. 2013 Jul [cited 2020 0ct 19]; 24(8):593. Available from: https://doi.org/10.1177/0956462413482811

29. O'Farrell N, Hoosen A, Kingston M. 2018 UK national guideline for the management of donovanosis. Int J STD AIDS [Internet]. 2018 Sep [cited 2020 0ct 19]; 29(10):946-8. Available from: https://doi.org/10.1177/0956462418770319

30. Prabhakar P, Narayanan P, Deshpande GR, Das A, Neilsen G, Mehendale S, et al. Genital ulcer disease in india: etiologies and performance of current syndrome guidelines. Sex Transm Dis [Internet]. 2012 Nov [cited 2020 0ct 19]; 39(11):906-10. Available from: https://doi.org/10.1097/olq.0b013e3182663e22

31. Brasil. Ministério da Saúde. Portaria MS/GM n ${ }^{\circ} 1.984$, de 12 de setembro de 2014. Define a lista nacional de doenças e agravos de notificação compulsória, na forma do Anexo, a serem monitorados por meio da estratégia de vigilância em unidades sentinelas e suas diretrizes [Internet]. Diário Oficial da União, Brasília (DF), 2014 set 15 [citado 2020 maio 31]; Seção 1:59. Disponível em: http://www.acm.org.br/acm/acamt/ documentos/emfoco/portaria-n-1984-12-09-2014.pdf.

32. Ministério da Saúde (BR). Secretaria de Vigilância em Saúde. Coordenação-Geral de Vigilância das Infecções Sexualmente Transmissíveis. Vigilância epidemiológica das infecções sexualmente transmissíveis no Brasil. Bol Epidemiol [Internet]. 2020 fev [citado 2020 jun 9]; 51(8):11-5. Disponível em: https://www.saude.gov.br/images/pdf/2020/ fevereiro/21/Boletim-epidemiologico-SVS-08.pdf.

33. Bazzo ML, Golfetto L, Gaspar PC, Pires AF, Ramos MC, Franchini M, et al. First nationwide antimicrobial susceptibility surveillance for Neisseria gonorrhoeae in Brazil, 2015-16. J Antimicrob Chemother [Internet]. 2018 [cited 2020 0ct 19]; 73(7):1854-61. Available from: https://doi.org/10.1093/jac/dky090

34. Sehgal VN, Pandhi D, Khurana A. Nonspecific genital ulcers. Clin Dermatol [Internet]. $2014 \mathrm{Feb}$ [cited 2020 Aug 6]; 32(2):259-74. Available from: https:// doi.org/10.1016/j.clindermatol.2013.08.024

35. Patel R, Green J, Clarke E, Seneviratne K, Abbt N, Evans $\mathrm{C}$, et al. 2014 UK national guideline for the management of anogenital herpes. Int J STD AIDS [Internet]. 2015 0ct [cited 2020 0ct 19]; 26(11):763-76. Available from: https://doi.org/10.1177/0956462415580512 
36. Gnann JW, Whitley RJ. Genital herpes. N Engl J Med [Intenet]. 2016 Aug [cited 2020 oct 19]; 375:666-74. Available from: https:// doi.org/10.1056/NEJMcp1603178

37. Foley E, Clarke E, Beckett VA, Harrison S, Pillai A, FitzGerald M, et al. Management of genital herpes in pregnancy [Internet]. London: BASHH; 2014 [cited 2020 0ct 19]. Available from: https://www.rcog.org.uk/globalassets/documents/ guidelines/management-genital-herpes.pdf.

38. Govender D, Narddok K, Chetty R. Granuloma inguinale: an usual cause of otitis media and mastoiditis in children. Am J Clin Pathol [Internet]. 1997
Novv [cited 2020 0ct 19]; 108(5):510-4. Available from: https://doi.org/10.1093/ajcp/108.5.510

39. Scott CW, Harper D, Jason RS. Neonatal granuloma venereum. Am J Dis Child [Internet]. 1953 Mar [cited 2020 0ct 19]; 85(3):308-15. Available form: https:// doi.org/10.1001/archpedi.1953.02050070320006

40. Ramdial PK, Sing Y, Ramburan A, Naidu TK, Samuel EY, Bagratee JS, et al. Infantile donovanosis presenting as external auditory canal polyps. A diagnostic trap. Am J Dermatopathol [Internet]. 2012 Dec [cited 2020 0ct 19]; 34(8):818-21. Available from: https://doi.org/10.1097/DAD.0b013e3182540ccb

\begin{abstract}
Infections that cause genital ulcers are one of the themes comprising the Clinical Protocol and Therapeutic Guidelines for Comprehensive Care for People with Sexually Transmitted Infections, published by the Brazilian Ministry of Health in 2020. The Protocol and Guidelines have been developed based on scientific evidence and validated in discussions with specialists. This article addresses clinical genital ulcer syndrome caused by sexually transmitted infections, and its most common etiological agents: Treponema pallidum (syphilis), herpes simplex virus-2 (genital herpes) and berpes simplex virus-1 (perioral berpes), Haemophilus ducreyi (chancroid), Chlamydia trachomatis serotypes L1, L2 and L3 (venereal lymphogranuloma), and Klebsiella granulomatis (donovanosis). Epidemiological and clinical aspects of these infections are presented, as well as guidelines for their diagnosis and treatment, in addition to strategies for surveillance, prevention and control actions, with the purpose of supporting bealth managers and professionals in the qualification of care.

Keywords: Syphilis; Chancre; Herpes Genitalis; Chancroid; Lymphogranuloma Venereum; Granuloma Inguinale.
\end{abstract}

\section{Resumen}

El tema de las infecciones que causan úlcera genital hace parte del Protocolo Clínico y Directrices Terapéuticas para Atención Integral a las Personas con Infecciones de Transmisión Sexual, publicado por el Ministerio de Salud de Brasil en 2020. Dicho documento fue elaborado con base en evidencias científicas $y$ validado en discusiones con expertos. Este artículo trata del síndrome de úlcera genital clínica provocada por infecciones de transmisión sexual, con sus agentes etiológicos más comunes: Treponema pallidum (sífilis), virus del herpes simple-1 (herpes genital) y virus del berpes simple-2 (herpes perioral), Haemophilus ducreyi (chancroide), Chlamydia trachomatis, serotipos L1, L2 y L3 (linfogranuloma venéreo), y Klebsiella granulomatis (donovanosis). Se presentan aspectos epidemiológicos y clinicos de esas infecciones, bien como pautas para su diagnóstico y tratamiento, además de estrategias para acciones de monitoreo epidemiológico, prevención y control, a fin de contribuir con gerentes y personal de salud en la calificación de la asistencia.

Palabras clave: Sifilis; Chancro; Herpes Genital; Chancroide; Linfogranuloma Venéreo; Granuloma Inguinal.

Recebido em 07/08/2020

Aprovado em 05/10/2020 


\section{Errata}

No artigo "Protocolo Brasileiro para Infecções Sexualmente Transmissíveis 2020: infecções que causam úlcera genital", doi: 10.1590/\$1679-4974202100010.esp1, Figura 1 - Recomendações para manejo de infecções que causam úlcera genital e Figura 3 - Tratamento de úlceras genitais com diagnóstico de sífilis, cancroide, linfogranuloma venéreo ou donovanose, publicado no periódico Epidemiologia e Serviços de Saúde, 30(Esp.1):1-12, nas páginas 6 e 8:

Figura 1 - Recomendações para manejo de infecções que causam úlcera genital

Onde se lia:

Visualização de treponemas móveis na microscopia de campo?

Leia-se:

Visualização de treponemas móveis na microscopia de campo escuro?

Figura 3 - Tratamento de úlceras genitais com diagnóstico de sífilis, cancroide, linfogranuloma venéreo ou donovanose

Onde se lia:

\begin{tabular}{|c|c|c|c|}
\hline $\begin{array}{l}\text { Infecção sexualmente } \\
\text { transmissível }\end{array}$ & Primeira opção & Alternativa & Comentários \\
\hline \multirow[b]{2}{*}{ Sífilis (cancro duro) } & \multirow{2}{*}{$\begin{array}{l}\text { Benzilpenicilina benzatina } \\
2,4 \text { milhões de unidades } \\
\text { internacionais (UI), } \\
\text { intramuscular (IM), dose } \\
\text { única (1,2 milhão Ul em cada } \\
\text { glúte0) }\end{array}$} & \multirow[b]{2}{*}{$\begin{array}{l}\text { Doxiciclina } 100 \mathrm{mg}, 12 / 12 \mathrm{~h} \text {, via } \\
\text { oral (V0), por } 15 \text { dias }\end{array}$} & $\begin{array}{l}\text { Tratamento para sífilis recente: sífilis primária, } \\
\text { secundária e latente recente (com até um ano de } \\
\text { evolução). }\end{array}$ \\
\hline & & & $\begin{array}{l}\text { Se considerada sífilis tardia: tratar com } \\
\text { benzilpenicilina benzatina 2,4 milhões UI, IM, } \\
\text { semanal ( } 1,2 \text { milhão UI em cada glúteo), por } \\
3 \text { semanas (dose total: } 7,2 \text { milhões UI, IM). } \\
\text { Alternativa: doxiciclinaa 100mg, 12/12h, V0, por } \\
30 \text { dias. }\end{array}$ \\
\hline \multirow{3}{*}{ Cancroide } & \multirow{3}{*}{$\begin{array}{l}\text { Azitromicina } 500 \mathrm{mg}, 2 \\
\text { comprimidos, V0, dose única }\end{array}$} & \multirow{3}{*}{$\begin{array}{l}\text { Ceftriaxona } 250 \mathrm{mg}, \mathrm{IM} \text {, dose } \\
\text { única ou ciprofloxacino } 500 \mathrm{mg}, 1 \\
\text { comprimido, V0, 2x/dia, por } 3 \text { dias }\end{array}$} & $\begin{array}{l}0 \text { tratamento sistêmico deve ser acompanhado de } \\
\text { medidas locais de higiene. }\end{array}$ \\
\hline & & & $\begin{array}{l}0 \text { prolongamento da terapia pode ser necessário } \\
\text { até a resolução da sintomatologia. }\end{array}$ \\
\hline & & & $\begin{array}{l}\text { A antibioticoterapia não tem efeito expressivo } \\
\text { na duração da linfadenopatia inguinal, mas os } \\
\text { sintomas agudos são frequentemente erradicados } \\
\text { de modo rápido. }\end{array}$ \\
\hline Linfogranuloma venéreo & $\begin{array}{l}\text { Doxiciclina } 100 \mathrm{mg}, \mathrm{V} 0,1 \\
\text { comprimido, 2x/dia, por } 21 \\
\text { dias }\end{array}$ & $\begin{array}{l}\text { Azitromicina } 500 \mathrm{mg}, 2 \\
\text { comprimidos, V0, 1x/semana, } \\
\text { por } 21 \text { dias (preferencial nas } \\
\text { gestantes) }\end{array}$ & $\begin{array}{l}\text { Os antibióticos não revertem sequelas como } \\
\text { estenose retal ou elefantíase genital. }\end{array}$ \\
\hline
\end{tabular}


Continuação

\begin{tabular}{|c|c|c|c|}
\hline $\begin{array}{l}\text { Infecção sexualmente } \\
\text { transmissível }\end{array}$ & Primeira opção & Alternativa & Comentários \\
\hline \multirow{3}{*}{ Donovanose } & \multirow{3}{*}{$\begin{array}{l}\text { Azitromicina } 500 \mathrm{mg}, 2 \\
\text { comprimidos, } \mathrm{V} 0,1 \mathrm{x} / \text { semana, } \\
\text { por pelo menos três semanas, } \\
\text { ou até a cicatrização das lesões }\end{array}$} & \multirow{3}{*}{$\begin{array}{l}\text { Doxiciclina } 100 \mathrm{mg}, 1 \text { comprimido, } \\
\text { V0, } 2 x / \text { dia, por pelo menos } 21 \\
\text { dias, ou até } 0 \text { desaparecimento } \\
\text { completo das lesões ou } \\
\text { ciprofloxacino } 500 \mathrm{mg}, 1 \text { e } 1 / 2 \\
\text { comprimido, V0, } 2 x / \text { dia, por } \\
\text { pelo menos } 21 \text { dias, ou até a } \\
\text { cicatrização das lesões (dose } \\
\text { total: } 750 \mathrm{mg} \text { ) ou sulfametoxazol- } \\
\text { trimetoprima ( } 400 / 80 \mathrm{mg}), 2 \\
\text { comprimidos, V0, } 2 \text { x/dia, por } \\
\text { no mínimo } 3 \text { semanas, ou até a } \\
\text { cicatrização das lesões }\end{array}$} & $\begin{array}{l}\text { Não havendo resposta na aparência da lesão nos } \\
\text { primeiros dias de tratamento com ciprofloxacino, } \\
\text { recomenda-se adicionar um aminoglicosídeo, } \\
\text { como a gentamicina, } 1 \mathrm{mg} / \mathrm{kg} / \text { dia, endovenoso, } \\
3 \mathrm{x} / \text { dia, por pelo menos três semanas, ou até } \\
\text { cicatrização das lesões. }\end{array}$ \\
\hline & & & $\begin{array}{l}\text { Em pessoas vivendo com HIV, sugerem-se } \\
\text { os mesmos esquemas terapêuticos; } 0 \text { uso de } \\
\text { terapia parenteral com a gentamicina deve ser } \\
\text { considerado nos casos mais graves. }\end{array}$ \\
\hline & & & $\begin{array}{l}\text { As sequelas da destruição tecidual ou obstrução } \\
\text { linfática podem exigir correção cirúrgica. }\end{array}$ \\
\hline
\end{tabular}

Leia-se:

\begin{tabular}{|c|c|c|c|}
\hline $\begin{array}{l}\text { Infecção sexualmente } \\
\text { transmissível }\end{array}$ & Primeira opção & Alternativa & Comentários \\
\hline Sífilis (cancro duro) & $\begin{array}{l}\text { Benzilpenicilina benzatina } \\
2,4 \text { milhões de unidades } \\
\text { internacionais (UI), } \\
\text { intramuscular (IM), dose } \\
\text { única (1,2 milhão Ul em cada } \\
\text { glúteo) }\end{array}$ & $\begin{array}{l}\text { Doxiciclina } 100 \mathrm{mg}, 12 / 12 \mathrm{~h} \text {, via oral } \\
\text { (V0), por } 15 \text { dias }\end{array}$ & $\begin{array}{l}\text { Tratamento para sífilis recente: sífilis } \\
\text { primária, secundária e latente recente (com } \\
\text { até um ano de evolução). } \\
\text { Se considerada sífilis tardia: tratar com } \\
\text { benzilpenicilina benzatina } 2,4 \text { milhões UI, } \\
\text { IM, semanal (1,2 milhão Ul em cada glúteo), } \\
\text { por } 3 \text { semanas (dose total: } 7,2 \text { milhões UI, } \\
\text { IM). Alternativa: doxiciclinaa } 100 \mathrm{mg}, 12 / 12 \mathrm{~h} \text {, } \\
\text { V0, por } 30 \text { dias. }\end{array}$ \\
\hline Cancroide & $\begin{array}{l}\text { Azitromicina 500mg, } 2 \\
\text { comprimidos, V0, dose única }\end{array}$ & $\begin{array}{l}\text { Ceftriaxona } 250 \mathrm{mg}, \mathrm{IM} \text {, dose única ou } \\
\text { ciprofloxacino } 500 \mathrm{mg}, 1 \text { comprimido, } \\
\text { V0, } 2 x / \text { dia, por } 3 \text { dias }\end{array}$ & $\begin{array}{l}0 \text { tratamento sistêmico deve ser } \\
\text { acompanhado de medidas locais de higiene. }\end{array}$ \\
\hline Linfogranuloma venéreo & $\begin{array}{l}\text { Doxiciclina } 100 \mathrm{mg}, \mathrm{V} 0,1 \\
\text { comprimido, } 2 x / \text { dia, por } 21 \\
\text { dias }\end{array}$ & $\begin{array}{l}\text { Azitromicina } 500 \mathrm{mg}, 2 \text { comprimidos, V0, } \\
1 \mathrm{x} / \text { semana, por } 21 \text { dias (preferencial nas } \\
\text { gestantes) }\end{array}$ & $\begin{array}{l}0 \text { prolongamento da terapia pode ser } \\
\text { necessário até a resolução da sintomatologia. } \\
\text { A antibioticoterapia não tem efeito } \\
\text { expressivo na duração da linfadenopatia } \\
\text { inguinal, mas os sintomas agudos são } \\
\text { frequentemente erradicados de modo rápido. } \\
\text { Os antibióticos não revertem sequelas como } \\
\text { estenose retal ou elefantíase genital. }\end{array}$ \\
\hline Donovanose & $\begin{array}{l}\text { Azitromicina } 500 \mathrm{mg}, 2 \\
\text { comprimidos, } \mathrm{V} 0,1 \mathrm{x} / \mathrm{semana}, \\
\text { por pelo menos três semanas, } \\
\text { ou até a cicatrização das lesões }\end{array}$ & $\begin{array}{l}\text { Doxiciclina } 100 \mathrm{mg}, 1 \text { comprimido, } \\
\text { V0, } 2 x / \text { dia, por pelo menos } 21 \text { dias, ou } \\
\text { até o desaparecimento completo das } \\
\text { lesões ou ciprofloxacino } 500 \mathrm{mg}, 1 \mathrm{e}^{1 / 2} 2 \\
\text { comprimido, } \mathrm{V} 0,2 \mathrm{x} / \text { dia, por pelo menos } \\
21 \text { dias, ou até a cicatrização das lesões } \\
\text { (dose total: } 750 \mathrm{mg} \text { ) ou sulfametoxazol- } \\
\text { trimetoprima ( } 400 / 80 \mathrm{mg}), 2 \\
\text { comprimidos, V0, } 2 x / \text { dia, por no mínimo } \\
3 \text { semanas, ou até a cicatrização das } \\
\text { lesões }\end{array}$ & $\begin{array}{l}\text { Não havendo resposta na aparência da } \\
\text { lesão nos primeiros dias de tratamento com } \\
\text { ciprofloxacino, recomenda-se adicionar um } \\
\text { aminoglicosídeo, como a gentamicina, 1mg/ } \\
\mathrm{kg} / \text { dia, endovenoso, 3x/dia, por pelo menos } \\
\text { três semanas, ou até cicatrização das lesões. } \\
\text { Em pessoas vivendo com HIV, sugerem-se } \\
\text { os mesmos esquemas terapêuticos; } 0 \text { uso de } \\
\text { terapia parenteral com a gentamicina deve } \\
\text { ser considerado nos casos mais graves. } \\
\text { As sequelas da destruição tecidual ou } \\
\text { obstrução linfática podem exigir correção } \\
\text { cirúrgica. }\end{array}$ \\
\hline
\end{tabular}

